\title{
Projection methods of iterative solutions in Hilbert spaces
}

Feng Gu and Jing Lu*

"Correspondence:

wllujing@sina.com

zjlujing@yeah.net

Department of Mathematics,

Hangzhou Normal University,

Hangzhou, 310036, China

\begin{abstract}
In this paper, zero points of the sum of two monotone mappings, solutions of a monotone variational inequality, and fixed points of a nonexpansive mapping are investigated based on a hybrid projection iterative algorithm. Strong convergence of the purposed iterative algorithm is obtained in the framework of real Hilbert spaces without any compact assumptions.
\end{abstract}

MSC: 47H05; 47H09; 47J25; 90C33

Keywords: fixed point; monotone operator; nonexpansive mapping; variational inequality; zero point

\section{Introduction and preliminaries}

Throughout this paper, we always assume that $H$ is a real Hilbert space with an inner product $\langle\cdot, \cdot\rangle$ and a norm $\|\cdot\|$. Let $C$ be a nonempty, closed, and convex subset of $H$. Let $S: C \rightarrow C$ be a nonlinear mapping. $F(S)$ stands for the fixed point set of $S$; that is, $F(S):=\{x \in C: x=T x\}$.

Recall that $S$ is said to be nonexpansive iff

$$
\|S x-S y\| \leq\|x-y\|, \quad \forall x, y \in C .
$$

If $C$ is a bounded, closed, and convex subset of $H$, then $F(S)$ is not empty, closed, and convex; see [1].

Let $A: C \rightarrow H$ be a mapping. Recall that $A$ is said to be inverse-strongly monotone iff there exists a constant $\alpha>0$ such that

$$
\langle A x-A y, x-y\rangle \geq \alpha\|A x-A y\|^{2}, \quad \forall x, y \in C .
$$

For such a case, $A$ is also said to be $\alpha$-inverse-strongly monotone.

$A$ is said to be monotone iff

$$
\langle A x-A y, x-y\rangle \geq 0, \quad \forall x, y \in C .
$$

Recall that the classical variational inequality is to find an $x \in C$ such that

$$
\langle A x, y-x\rangle \geq 0, \quad \forall y \in C .
$$

๑) 2012 Gu and Lu; licensee Springer. This is an Open Access article distributed under the terms of the Creative Commons Attribution License (http://creativecommons.org/licenses/by/2.0), which permits unrestricted use, distribution, and reproduction in any medium, provided the original work is properly cited. 
In this paper, we use $\operatorname{VI}(C, A)$ to denote the solution set of (1.1). It is known that $x \in C$ is a solution of (1.1) if and only if $x$ is a fixed point of the mapping $\operatorname{Proj}_{C}(I-r A)$, where $r>0$ is a constant, $I$ stands for the identity mapping, and $\operatorname{Proj}_{C}$ stands for the metric projection from $H$ onto $C$. If $A$ is $\alpha$-inverse-strongly monotone and $r \in(0,2 \alpha]$, then the mapping $\operatorname{Proj}_{C}(I-r A)$ is nonexpansive; see [2] for more details. It follows that $\operatorname{VI}(C, A)$ is closed and convex.

Monotone variational inequality theory has emerged as a fascinating branch of mathematical and engineering sciences with a wide range of applications in industry, finance, economics, ecology, social, regional, pure, and applied sciences. In recent years, much attention has been given to developing efficient numerical methods for treating solution problems of monotone variational inequality. The gradient-projection method is a powerful tool for solving constrained convex optimization problems and has extensively been studied; see [3-5] and the references therein. It has recently been applied to solving split feasibility problems which find applications in image reconstructions and the intensity modulated radiation theory; see [6-9] and the references therein. However, the gradientprojection method requires the operator to be strongly monotone and Lipschitz continuous. These strong conditions rule out many applications. Extra gradient-projection method which was first introduce by Korpelevich [10] in the finite dimensional Euclidean space has been studied recently for relaxing the strong monotonicity of operators; see [11$13]$ and the references therein.

Recall that a set-valued mapping $M: H \rightrightarrows H$ is said to be monotone iff, for all $x, y \in H$, $f \in M x$ and $g \in M y$ imply $\langle x-y, f-g\rangle>0$. A monotone mapping $M: H \rightrightarrows H$ is maximal iff the graph $\operatorname{Graph}(M)$ of $R$ is not properly contained in the graph of any other monotone mapping. It is known that a monotone mapping $M$ is maximal if and only if, for any $(x, f) \in$ $H \times H,\langle x-y, f-g\rangle \geq 0$, for all $(y, g) \in \operatorname{Graph}(M)$ implies $f \in R x$.

For a maximal monotone operator $M$ on $H$ and $r>0$, we may define the single-valued resolvent $J_{r}: H \rightarrow D(M)$, where $D(M)$ denotes the domain of $M$. It is known that $J_{r}$ is firmly nonexpansive, and $M^{-1}(0)=F\left(J_{r}\right)$, where $F\left(J_{r}\right):=\left\{x \in D(M): x=J_{r} x\right\}$ and $M^{-1}(0)$ : $\{x \in H: 0 \in M x\}$.

Recently, variational inequalities, fixed point problems, and zero point problems have been investigated by many authors based on iterative methods; see, for example, [14-32] and the references therein. In this paper, zero point problems of the sum of a maximal monotone operator and an inverse-strongly monotone mapping, solution problems of a monotone variational inequality, and fixed point problems of a nonexpansive mapping are investigated. A hybrid iterative algorithm is considered for analyzing the convergence of iterative sequences. Strong convergence theorems are established in the framework of real Hilbert spaces without any compact assumptions.

In order to prove our main results, we also need the following definitions and lemmas.

Lemma 1.1 Let $C$ be a nonempty, closed, and convex subset of $H$. Then the following inequality holds:

$$
\left\|x-\operatorname{Proj}_{C} x\right\|^{2}+\left\|y-\operatorname{Proj}_{C}\right\|^{2} \leq\|x-y\|^{2}, \quad \forall x \in H, y \in C .
$$

Lemma 1.2 [1] Let C be a nonempty, closed, and convex subset of $H$. Let $S: C \rightarrow C$ be a nonexpansive mapping. Then the mapping $I-S$ is demiclosed at zero, that is, if $\left\{x_{n}\right\}$ is a sequence in $C$ such that $x_{n} \rightarrow \bar{x}$ and $x_{n}-S x_{n} \rightarrow 0$, then $\bar{x} \in F(S)$. 
Lemma 1.3 Let $C$ be a nonempty, closed, and convex subset of $H, B: C \rightarrow H$ be a mapping, and $M: H \rightrightarrows H$ be a maximal monotone operator. Then $F\left(J_{r}(I-s B)\right)=(B+M)^{-1}(0)$.

Proof Notice that

$$
\begin{aligned}
p \in F\left(J_{r}(I-s B)\right) \quad \Longleftrightarrow p=J_{r}(I-s B) p \quad \Longleftrightarrow p-s B p \in p+s M p \\
\Longleftrightarrow 0 \in(B+M)^{-1}(0) \Longleftrightarrow p \in(B+M)^{-1}(0) .
\end{aligned}
$$

This completes the proof.

Lemma 1.4 [33] Let $C$ be a nonempty, closed, and convex subset of $H, A: C \rightarrow H$ be a Lipschitz monotone mapping, and $N_{C} x$ be the normal cone to $C$ at $x \in C$; that is, $N_{C} x=$ $\{y \in H:\langle x-u, y\rangle, \forall u \in C\}$. Define

$$
W x= \begin{cases}A x+N_{C} x, & x \in C, \\ \emptyset, & x \notin C .\end{cases}
$$

Then $W$ is maximal monotone and $0 \in W x$ if and only if $x \in \operatorname{VI}(C, A)$.

\section{Main results}

Now, we are in a position to give our main results.

Theorem 2.1 Let $C$ be a nonempty, closed, and convex subset of $H$. Let $S: C \rightarrow C$ be a nonexpansive mapping with a nonempty fixed point set, $A: C \rightarrow H$ be an $\alpha$-Lipschitz continuous and monotone mapping, and $B: C \rightarrow H$ be a $\beta$-inverse-strongly monotone mapping. Let $M: H \rightrightarrows H$ be a maximal monotone operator such that $D(M) \subset C$. Assume that $\mathcal{F}:=F(S) \cap(B+M)^{-1}(0) \cap \mathrm{VI}(C, A)$ is not empty. Let $\left\{x_{n}\right\}$ be a sequence generated by the following iterative process:

$$
\left\{\begin{array}{l}
x_{1} \in C, \\
C_{1}=C, \\
z_{n}=\operatorname{Proj}_{C}\left(J_{s_{n}}\left(x_{n}-s_{n} B x_{n}\right)-r_{n} A J_{s_{n}}\left(x_{n}-s_{n} B x_{n}\right)\right), \\
y_{n}=\alpha_{n} x_{n}+\left(1-\alpha_{n}\right) S \operatorname{Proj}_{C}\left(J_{s_{n}}\left(x_{n}-s_{n} B x_{n}\right)-r_{n} A z_{n}\right), \\
C_{n+1}=\left\{v \in C_{n}:\left\|y_{n}-v\right\| \leq\left\|x_{n}-v\right\|\right\}, \\
x_{n+1}=\operatorname{Proj}_{C_{n+1}} x_{1}, \quad n \geq 0,
\end{array}\right.
$$

where $J_{s_{n}}=\left(I+s_{n} M\right)^{-1},\left\{r_{n}\right\}$ is a sequence in $\left(0, \frac{1}{\alpha}\right),\left\{s_{n}\right\}$ is a sequence in $(0,2 \beta)$, and $\left\{\alpha_{n}\right\}$ is a sequence in $(0,1)$. Assume that the following restrictions are satisfied:

(a) $0<a \leq r_{n} \leq b<\frac{1}{\alpha}$;

(b) $0<c \leq s_{n} \leq d<2 \beta$;

(c) $0 \leq \alpha_{n} \leq e<1$,

where $a, b, c, d$, and e are real constants. Then the sequence $\left\{x_{n}\right\}$ converges strongly to $\operatorname{Proj}_{\mathcal{F}} x_{1}$.

Proof First, we show that $C_{n}$ is closed and convex for each $n \geq 1$. From the assumption, we see that $C_{1}=C$ is closed and convex. Suppose that $C_{m}$ is closed and convex for some 
$m \geq 1$. We show that $C_{m+1}$ is closed and convex for the same $m$. Let $v_{1}, v_{2} \in C_{m+1}$ and $v=t v_{1}+(1-t) v_{2}$, where $t \in(0,1)$. Notice that

$$
\left\|y_{m}-v\right\| \leq\left\|x_{m}-v\right\|
$$

is equivalent to

$$
\left\|y_{m}\right\|^{2}-\left\|x_{m}\right\|^{2}-2\left\langle v, y_{m}-x_{m}\right\rangle \geq 0
$$

It is clear that $v \in C_{m+1}$. This shows that $C_{n}$ is closed and convex for each $n \geq 1$.

Next, we show that $\mathcal{F} \subset C_{n}$ for each $n \geq 1$. Put $u_{n}=\operatorname{Proj}_{C}\left(v_{n}-r_{n} A z_{n}\right)$, where $v_{n}=J_{s_{n}}\left(x_{n}-\right.$ $\left.s_{n} B x_{n}\right)$. From the assumption, we see that $\mathcal{F} \subset C=C_{1}$. Suppose that $\mathcal{F} \subset C_{m}$ for some $m \geq 1$. For any $p \in \mathcal{F} \subset C_{m}$, we see from Lemma 1.1 that

$$
\begin{aligned}
\left\|u_{m}-p\right\|^{2} \leq & \left\|v_{m}-r_{m} A z_{m}-p\right\|^{2}-\left\|v_{m}-r_{m} A z_{m}-u_{m}\right\|^{2} \\
= & \left\|v_{m}-p\right\|^{2}-\left\|v_{m}-u_{m}\right\|^{2}+2 r_{m}\left\langle A z_{m}, p-u_{m}\right\rangle \\
= & \left\|v_{m}-p\right\|^{2}-\left\|v_{m}-u_{m}\right\|^{2}+2 r_{m}\left(\left\langle A z_{m}-A p, p-z_{m}\right\rangle+\left\langle A p, p-z_{m}\right\rangle\right. \\
& \left.+\left\langle A z_{m}, z_{m}-u_{m}\right\rangle\right) \\
\leq & \left\|v_{m}-p\right\|^{2}-\left\|v_{m}-z_{m}+z_{m}-u_{m}\right\|^{2}+2 r_{m}\left\langle A z_{m}, z_{m}-u_{m}\right\rangle \\
= & \left\|v_{m}-p\right\|^{2}-\left\|v_{m}-z_{m}\right\|^{2}-\left\|z_{m}-u_{m}\right\|^{2} \\
& +2\left\langle v_{m}-z_{m}-r_{m} A z_{m}, u_{m}-z_{m}\right\rangle .
\end{aligned}
$$

Notice that $A$ is Lipschitz continuous. In view of $z_{m}=\operatorname{Proj}_{C}\left(v_{m}-r_{m} A v_{m}\right)$, we find that

$$
\begin{aligned}
& \left\langle v_{m}-z_{m}-r_{m} A z_{m}, u_{m}-z_{m}\right\rangle \\
& \quad=\left\langle v_{m}-z_{m}-r_{m} A v_{m}, u_{m}-z_{m}\right\rangle+\left\langle r_{m} A v_{m}-r_{m} A z_{m}, u_{m}-z_{m}\right\rangle \\
& \quad \leq r_{m} \alpha\left\|v_{m}-z_{m}\right\|\left\|u_{m}-z_{m}\right\| .
\end{aligned}
$$

Substituting (2.3) into (2.2), we obtain that

$$
\begin{aligned}
\left\|u_{m}-p\right\|^{2} & \leq\left\|v_{m}-p\right\|^{2}-\left\|v_{m}-z_{m}\right\|^{2}-\left\|z_{m}-u_{m}\right\|^{2}+2 r_{m} \alpha\left\|v_{m}-z_{m}\right\|\left\|u_{m}-z_{m}\right\| \\
& \leq\left\|v_{m}-p\right\|^{2}-\left(1-r_{m}^{2} \alpha^{2}\right)\left\|v_{m}-z_{m}\right\|^{2}
\end{aligned}
$$

This in turn implies from restriction (a) that

$$
\begin{aligned}
\left\|y_{m}-p\right\|^{2} & \leq \alpha_{m}\left\|x_{m}-p\right\|^{2}+\left(1-\alpha_{m}\right)\left\|S u_{m}-p\right\|^{2} \\
& \leq \alpha_{m}\left\|x_{m}-p\right\|^{2}+\left(1-\alpha_{m}\right)\left\|u_{m}-p\right\|^{2} \\
& \leq \alpha_{m}\left\|x_{m}-p\right\|^{2}+\left(1-\alpha_{m}\right)\left(\left\|v_{m}-p\right\|^{2}-\left(1-r_{m}^{2} \alpha^{2}\right)\left\|v_{m}-z_{m}\right\|^{2}\right) \\
& \leq\left\|x_{m}-p\right\|^{2}-\left(1-\alpha_{m}\right)\left(1-r_{m}^{2} \alpha^{2}\right)\left\|v_{m}-z_{m}\right\|^{2} \\
& \leq\left\|x_{m}-p\right\|^{2} .
\end{aligned}
$$


This shows that $p \in C_{m+1}$. This proves that $\mathcal{F} \subset C_{n}$ for each $n \geq 1$. Note $x_{n}=\operatorname{Proj}_{C_{n}} x_{1}$. For each $p \in \mathcal{F} \subset C_{n}$, we have $\left\|x_{1}-x_{n}\right\| \leq\left\|x_{1}-p\right\|$. Since $B$ is inverse-strongly monotone, we see from Lemma 1.3 that $(B+M)^{-1}(0)$ is closed and convex. Since $A$ is Lipschitz continuous, we find that $\operatorname{VI}(C, A)$ is close and convex. This proves that $\mathcal{F}$ is closed and convex. It follows that

$$
\left\|x_{1}-x_{n}\right\| \leq\left\|x_{1}-\operatorname{Proj}_{\mathcal{F}} x_{1}\right\| \text {. }
$$

This implies that $\left\{x_{n}\right\}$ is bounded. Since $x_{n}=\operatorname{Proj}_{C_{n}} x_{1}$ and $x_{n+1}=\operatorname{Proj}_{C_{n+1}} x_{1} \in C_{n+1} \subset C_{n}$, we have

$$
\begin{aligned}
0 & \leq\left\langle x_{1}-x_{n}, x_{n}-x_{n+1}\right\rangle \\
& =\left\langle x_{1}-x_{n}, x_{n}-x_{1}+x_{1}-x_{n+1}\right\rangle \\
& \leq-\left\|x_{1}-x_{n}\right\|^{2}+\left\|x_{1}-x_{n}\right\|\left\|x_{1}-x_{n+1}\right\| .
\end{aligned}
$$

It follows that

$$
\left\|x_{n}-x_{1}\right\| \leq\left\|x_{n+1}-x_{1}\right\| .
$$

This proves that $\lim _{n \rightarrow \infty}\left\|x_{n}-x_{1}\right\|$ exists. Notice that

$$
\begin{aligned}
\| x_{n} & -x_{n+1} \|^{2} \\
& =\left\|x_{n}-x_{1}\right\|^{2}+2\left\langle x_{n}-x_{1}, x_{1}-x_{n+1}\right\rangle+\left\|x_{1}-x_{n+1}\right\|^{2} \\
& =\left\|x_{n}-x_{1}\right\|^{2}-2\left\|x_{n}-x_{1}\right\|^{2}+2\left\langle x_{n}-x_{1}, x_{n}-x_{n+1}\right\rangle+\left\|x_{1}-x_{n+1}\right\|^{2} \\
& \leq\left\|x_{1}-x_{n+1}\right\|^{2}-\left\|x_{n}-x_{1}\right\|^{2} .
\end{aligned}
$$

It follows that

$$
\lim _{n \rightarrow \infty}\left\|x_{n}-x_{n+1}\right\|=0
$$

In view of $x_{n+1}=\operatorname{Proj}_{C_{n+1}} x_{1} \in C_{n+1}$, we see that

$$
\left\|y_{n}-x_{n+1}\right\| \leq\left\|x_{n}-x_{n+1}\right\| .
$$

This implies that

$$
\left\|y_{n}-x_{n}\right\| \leq\left\|y_{n}-x_{n+1}\right\|+\left\|x_{n}-x_{n+1}\right\| \leq 2\left\|x_{n}-x_{n+1}\right\| .
$$

From (2.7), we find that

$$
\lim _{n \rightarrow \infty}\left\|x_{n}-y_{n}\right\|=0 .
$$


Since $B$ is $\beta$-inverse-strongly monotone, we see from restriction (b) that

$$
\begin{aligned}
\left\|\left(I-s_{n} B\right) x-\left(I-s_{n} B\right) y\right\|^{2} & =\|x-y\|^{2}-2 s_{n}\langle x-y, B x-B y\rangle+s_{n}^{2}\|B x-B y\|^{2} \\
& \leq\|x-y\|^{2}-s_{n}\left(2 \beta-s_{n}\right)\|B x-B y\|^{2} \\
& \leq\|x-y\|^{2}, \quad \forall x, y \in C .
\end{aligned}
$$

This implies from (2.5) that

$$
\begin{aligned}
\left\|y_{n}-p\right\|^{2} & \leq \alpha_{n}\left\|x_{n}-p\right\|^{2}+\left(1-\alpha_{n}\right)\left\|v_{n}-p\right\|^{2} \\
& =\alpha_{n}\left\|x_{n}-p\right\|^{2}+\left(1-\alpha_{n}\right)\left\|J_{s_{n}}\left(x_{n}-s_{n} B x_{n}\right)-J_{s_{n}}\left(p-s_{n} B p\right)\right\|^{2} \\
& \leq\left\|x_{n}-p\right\|^{2}-\left(1-\alpha_{n}\right) s_{n}\left(2 \beta-s_{n}\right)\left\|B x_{n}-B p\right\|^{2} .
\end{aligned}
$$

It follows that

$$
\begin{aligned}
\left(1-\alpha_{n}\right) s_{n}\left(2 \beta-s_{n}\right)\left\|B x_{n}-B p\right\|^{2} & \leq\left\|x_{n}-p\right\|^{2}-\left\|y_{n}-p\right\|^{2} \\
& \leq\left\|x_{n}-y_{n}\right\|\left(\left\|x_{n}-p\right\|+\left\|y_{n}-p\right\|\right) .
\end{aligned}
$$

In view of restrictions (b) and (c), we find from (2.8) that

$$
\lim _{n \rightarrow \infty}\left\|B x_{n}-B p\right\|=0
$$

Since $J_{s_{n}}$ is firmly nonexpansive, we find that

$$
\begin{aligned}
\left\|v_{n}-p\right\|^{2}= & \left\|J_{s_{n}}\left(x_{n}-s_{n} B x_{n}\right)-J_{s_{n}}\left(p-s_{n} B p\right)\right\|^{2} \\
\leq & \left\langle v_{n}-p,\left(x_{n}-s_{n} B x_{n}\right)-\left(p-s_{n} B p\right)\right\rangle \\
= & \frac{1}{2}\left(\left\|v_{n}-p\right\|^{2}+\left\|\left(x_{n}-s_{n} B x_{n}\right)-\left(p-s_{n} B p\right)\right\|^{2}\right. \\
& \left.-\left\|\left(v_{n}-p\right)-\left(\left(x_{n}-s_{n} B x_{n}\right)-\left(p-s_{n} B p\right)\right)\right\|^{2}\right) \\
\leq & \frac{1}{2}\left(\left\|v_{n}-p\right\|^{2}+\left\|x_{n}-p\right\|^{2}-\left\|v_{n}-x_{n}+s_{n}\left(B x_{n}-B p\right)\right\|^{2}\right) \\
= & \frac{1}{2}\left(\left\|v_{n}-p\right\|^{2}+\left\|x_{n}-p\right\|^{2}-\left\|v_{n}-x_{n}\right\|^{2}-s_{n}^{2}\left\|B x_{n}-B p\right\|^{2}\right. \\
& \left.-2 s_{n}\left\langle v_{n}-x_{n}, B x_{n}-B p\right\rangle\right) \\
\leq & \frac{1}{2}\left(\left\|v_{n}-p\right\|^{2}+\left\|x_{n}-p\right\|^{2}-\left\|v_{n}-x_{n}\right\|^{2}+2 s_{n}\left\|v_{n}-x_{n}\right\|\left\|B x_{n}-B p\right\|\right) .
\end{aligned}
$$

This in turn implies that

$$
\left\|v_{n}-p\right\|^{2} \leq\left\|x_{n}-p\right\|^{2}-\left\|v_{n}-x_{n}\right\|^{2}+2 s_{n}\left\|v_{n}-x_{n}\right\|\left\|B x_{n}-B p\right\| .
$$

Combining (2.5) with (2.10), we arrive at

$$
\begin{aligned}
\left\|y_{n}-p\right\|^{2} & \leq \alpha_{n}\left\|x_{n}-p\right\|^{2}+\left(1-\alpha_{n}\right)\left\|v_{n}-p\right\|^{2} \\
& \leq\left\|x_{n}-p\right\|^{2}-\left(1-\alpha_{n}\right)\left\|v_{n}-x_{n}\right\|^{2}+2 s_{n}\left\|v_{n}-x_{n}\right\|\left\|B x_{n}-B p\right\| .
\end{aligned}
$$


It follows that

$$
\begin{aligned}
\left(1-\alpha_{n}\right)\left\|v_{n}-x_{n}\right\|^{2} & \leq\left\|x_{n}-p\right\|^{2}-\left\|y_{n}-p\right\|^{2}+2 s_{n}\left\|v_{n}-x_{n}\right\|\left\|B x_{n}-B p\right\| \\
& \leq\left\|x_{n}-y_{n}\right\|\left(\left\|x_{n}-p\right\|+\left\|y_{n}-p\right\|\right)+2 s_{n}\left\|v_{n}-x_{n}\right\|\left\|B x_{n}-B p\right\| .
\end{aligned}
$$

In view of (2.8) and (2.9), we see from restriction (c) that

$$
\lim _{n \rightarrow \infty}\left\|v_{n}-x_{n}\right\|=0
$$

On the other hand, we find from (2.5) that

$$
\begin{aligned}
\left(1-\alpha_{n}\right)\left(1-r_{n}^{2} \alpha^{2}\right)\left\|v_{n}-z_{n}\right\|^{2} & \leq\left\|x_{n}-p\right\|^{2}-\left\|y_{n}-p\right\|^{2} \\
& \leq\left\|x_{n}-y_{n}\right\|\left(\left\|x_{n}-p\right\|+\left\|y_{n}-p\right\|\right) .
\end{aligned}
$$

In view of restrictions (a) and (c), we obtain from (2.8) that

$$
\lim _{n \rightarrow \infty}\left\|v_{n}-z_{n}\right\|=0
$$

Notice that

$$
\begin{aligned}
\left\|u_{n}-z_{n}\right\|^{2} & =\left\|P_{C}\left(v_{n}-r_{n} A z_{n}\right)-P_{C}\left(v_{n}-r_{n} A v_{n}\right)\right\|^{2} \\
& \leq\left\|\left(v_{n}-r_{n} A z_{n}\right)-\left(v_{n}-r_{n} A v_{n}\right)\right\|^{2} \\
& \leq r_{n}^{2} \alpha^{2}\left\|z_{n}-v_{n}\right\|^{2} .
\end{aligned}
$$

Thanks to (2.12), we arrive at

$$
\lim _{n \rightarrow \infty}\left\|u_{n}-z_{n}\right\|=0
$$

Notice that

$$
\begin{aligned}
\left\|x_{n}-S x_{n}\right\| & \leq\left\|x_{n}-S u_{n}\right\|+\left\|S u_{n}-S x_{n}\right\| \\
& \leq \frac{\left\|x_{n}-y_{n}\right\|}{1-\alpha_{n}}+\left\|u_{n}-x_{n}\right\| \\
& \leq \frac{\left\|x_{n}-y_{n}\right\|}{1-\alpha_{n}}+\left\|u_{n}-z_{n}\right\|+\left\|z_{n}-v_{n}\right\|+\left\|v_{n}-x_{n}\right\| .
\end{aligned}
$$

In view of (2.8), (2.11), (2.12), and (2.13), we find from restriction (c) that

$$
\lim _{n \rightarrow \infty}\left\|x_{n}-S x_{n}\right\|=0
$$

Since $\left\{x_{n}\right\}$ is bounded, we find that there exists a subsequence $\left\{x_{n_{i}}\right\}$ of $\left\{x_{n}\right\}$ such that $x_{n_{i}} \rightarrow$ $q \in C$. From Lemma 1.2, we easily conclude that $q \in F(S)$.

Now, we are in a position to show that $x \in \operatorname{VI}(C, A)$. Define

$$
W x= \begin{cases}A x+N_{C} x, & x \in C, \\ \emptyset, & x \notin C .\end{cases}
$$


For any given $(x, y) \in G(W)$, we have $y-A x \in N_{C} x$. Since $u_{n} \in C$, we see from the definition of $N_{C}$

$$
\left\langle x-u_{n}, y-A x\right\rangle \geq 0 .
$$

In view of $u_{n}=P_{C}\left(v_{n}-r_{n} A z_{n}\right)$, we obtain that

$$
\left\langle x-u_{n}, u_{n}+r_{n} A z_{n}-v_{n}\right\rangle \geq 0
$$

and hence

$$
\left\langle x-u_{n}, \frac{u_{n}-v_{n}}{r_{n}}+A z_{n}\right\rangle \geq 0 .
$$

In view of (2.14) and (2.15), we find that

$$
\begin{aligned}
\left\langle x-u_{n_{i}}, y\right\rangle \geq & \left\langle x-u_{n_{i}}, A x\right\rangle \\
\geq & \left\langle x-u_{n_{i}}, A x\right\rangle-\left\langle x-u_{n_{i}}, \frac{u_{n_{i}}-v_{n_{i}}}{r_{n_{i}}}+A z_{n_{i}}\right\rangle \\
= & \left\langle x-u_{n_{i}}, A x-A u_{n_{i}}\right\rangle+\left\langle x-u_{n_{i}}, A u_{n_{i}}-A z_{n_{i}}\right\rangle \\
& -\left\langle x-u_{n_{i}}, \frac{u_{n_{i}}-v_{n_{i}}}{r_{n_{i}}}\right\rangle \\
\geq & \left\langle x-u_{n_{i}}, A u_{n_{i}}-A z_{n_{i}}\right\rangle-\left\langle x-u_{n_{i}}, \frac{u_{n_{i}}-v_{n_{i}}}{r_{n_{i}}}\right\rangle .
\end{aligned}
$$

Notice that

$$
\left\|x_{n}-u_{n}\right\| \leq\left\|x_{n}-v_{n}\right\|+\left\|v_{n}-z_{n}\right\|+\left\|z_{n}-u_{n}\right\| .
$$

It follows from (2.11), (2.12), and (2.13) that

$$
\lim _{n \rightarrow \infty}\left\|x_{n}-u_{n}\right\|=0
$$

Since $A$ is Lipschitz continuous, we find from (2.16) that

$$
\langle x-q, y\rangle \geq 0 .
$$

Since $W$ is maximal monotone, we conclude that $q \in W^{-1}(0)$. This proves that $q \in$ $\operatorname{VI}(C, A)$.

Finally, we prove that $q \in(B+M)^{-1}(0)$. Notice that

$$
x_{n}-s_{n} B x_{n} \in v_{n}+s_{n} M v_{n}
$$

that is,

$$
\frac{x_{n}-v_{n}}{s_{n}}-B x_{n} \in M v_{n}
$$


Let $\mu \in M \nu$. Since $M$ is monotone, we find from (2.17)

$$
\left\langle\frac{x_{n}-v_{n}}{s_{n}}-B x_{n}-\mu, v_{n}-v\right\rangle \geq 0
$$

In view of the restriction (b), we see that

$$
\langle-B q-\mu, q-v\rangle \geq 0
$$

This implies that $-B q \in M q$, that is, $q \in(B+M)^{-1}(0)$. This completes $q \in \mathcal{F}$. Assume that there exists another subsequence $\left\{x_{n_{j}}\right\}$ of $\left\{x_{n}\right\}$ which converges weakly to $q^{\prime} \in \mathcal{F}$. We can easily conclude from Opial's condition that $q=q^{\prime}$.

Finally, we show that $q=\operatorname{Proj}_{\mathcal{F}} x_{1}$ and $\left\{x_{n}\right\}$ converges strongly to $q$. This completes the proof of Theorem 2.1. In view of the weak lower semicontinuity of the norm, we obtain from (2.6) that

$$
\begin{aligned}
\left\|x_{1}-\operatorname{Proj}_{\mathcal{F}} x_{1}\right\| & \leq\left\|x_{1}-q\right\| \leq \liminf _{n \rightarrow \infty}\left\|x_{1}-x_{n}\right\| \\
& \leq \limsup _{n \rightarrow \infty}\left\|x_{1}-x_{n}\right\| \leq\left\|x_{1}-\operatorname{Proj}_{\mathcal{F}} x_{1}\right\|,
\end{aligned}
$$

which yields that $\lim _{n \rightarrow \infty}\left\|x_{1}-x_{n}\right\|=\left\|x_{1}-\operatorname{Proj}_{\mathcal{F}} x_{1}\right\|=\left\|x_{1}-q\right\|$. It follows that $\left\{x_{n}\right\}$ converges strongly to $\operatorname{Proj}_{\mathcal{F}} x_{1}$. This completes the proof.

If $B=0$, then Theorem 2.1 is reduced to the following.

Corollary 2.2 Let $C$ be a nonempty, closed, and convex subset of $H$. Let $S: C \rightarrow C$ be a nonexpansive mapping with a nonempty fixed point set and $A: C \rightarrow H$ be an $\alpha$-Lipschitz continuous and monotone mapping. Let $M: H \rightrightarrows H$ be a maximal monotone operator such that $D(M) \subset C$. Assume that $\mathcal{F}:=F(S) \cap M^{-1}(0) \cap \operatorname{VI}(C, A)$ is not empty. Let $\left\{x_{n}\right\}$ be a sequence generated by the following iterative process:

$$
\left\{\begin{array}{l}
x_{1} \in C, \\
C_{1}=C, \\
z_{n}=\operatorname{Proj}_{C}\left(J_{s_{n}} x_{n}-r_{n} A J_{s_{n}} x_{n}\right), \\
y_{n}=\alpha_{n} x_{n}+\left(1-\alpha_{n}\right) S \operatorname{Proj}_{C}\left(J_{s_{n}} x_{n}-r_{n} A z_{n}\right), \\
C_{n+1}=\left\{v \in C_{n}:\left\|y_{n}-v\right\| \leq\left\|x_{n}-v\right\|\right\}, \\
x_{n+1}=\operatorname{Proj}_{C_{n+1}} x_{1}, \quad n \geq 0,
\end{array}\right.
$$

where $J_{s_{n}}=\left(I+s_{n} M\right)^{-1},\left\{r_{n}\right\}$ is a sequence in $\left(0, \frac{1}{\alpha}\right),\left\{s_{n}\right\}$ is a sequence in $(0,+\infty)$, and $\left\{\alpha_{n}\right\}$ is a sequence in $(0,1)$. Assume that the following restrictions are satisfied:

(a) $0<a \leq r_{n} \leq b<\frac{1}{\alpha}$;

(b) $0<c \leq s_{n}<\infty$;

(c) $0 \leq \alpha_{n} \leq d<1$,

where $a, b, c$, and $d$ are real constants. Then the sequence $\left\{x_{n}\right\}$ converges strongly to $\operatorname{Proj}_{\mathcal{F}} x_{1}$.

If $M=0$, then $J_{s_{n}}=I$. Corollary 2.2 is reduced to the following. 
Corollary 2.3 Let $C$ be a nonempty, closed, and convex subset of $H$. Let $S: C \rightarrow C$ be a nonexpansive mapping with a nonempty fixed point set and $A: C \rightarrow H$ be an $\alpha$-Lipschitz continuous and monotone mapping. Assume that $\mathcal{F}:=F(S) \cap \operatorname{VI}(C, A)$ is not empty. Let $\left\{x_{n}\right\}$ be a sequence generated by the following iterative process:

$$
\left\{\begin{array}{l}
x_{1} \in C, \\
C_{1}=C \\
z_{n}=\operatorname{Proj}_{C}\left(x_{n}-r_{n} A x_{n}\right), \\
y_{n}=\alpha_{n} x_{n}+\left(1-\alpha_{n}\right) S \operatorname{Proj}_{C}\left(x_{n}-r_{n} A z_{n}\right), \\
C_{n+1}=\left\{v \in C_{n}:\left\|y_{n}-v\right\| \leq\left\|x_{n}-v\right\|\right\}, \\
x_{n+1}=\operatorname{Proj}_{C_{n+1}} x_{1}, \quad n \geq 0,
\end{array}\right.
$$

where $\left\{r_{n}\right\}$ is a sequence in $\left(0, \frac{1}{\alpha}\right)$, and $\left\{\alpha_{n}\right\}$ is a sequence in $(0,1)$. Assume that the following restrictions are satisfied:

(a) $0<a \leq r_{n} \leq b<\frac{1}{\alpha}$;

(b) $0 \leq \alpha_{n} \leq c<1$,

where $a, b$, and $c$ are real constants. Then the sequence $\left\{x_{n}\right\}$ converges strongly to $\operatorname{Proj}_{\mathcal{F}} x_{1}$.

If $A=0$, then Theorem 2.1 is reduced to the following.

Corollary 2.4 Let $C$ be a nonempty, closed, and convex subset of H. Let $S: C \rightarrow C$ be a nonexpansive mapping with a nonempty fixed point set and $B: C \rightarrow H$ be a $\beta$-inverse-strongly monotone mapping. Let $M: H \rightrightarrows H$ be a maximal monotone operator such that $D(M) \subset C$. Assume that $\mathcal{F}:=F(S) \cap(B+M)^{-1}(0)$ is not empty. Let $\left\{x_{n}\right\}$ be a sequence generated by the following iterative process:

$$
\left\{\begin{array}{l}
x_{1} \in C, \\
C_{1}=C, \\
y_{n}=\alpha_{n} x_{n}+\left(1-\alpha_{n}\right) S J_{s_{n}}\left(x_{n}-s_{n} B x_{n}\right), \\
C_{n+1}=\left\{v \in C_{n}:\left\|y_{n}-v\right\| \leq\left\|x_{n}-v\right\|\right\}, \\
x_{n+1}=\operatorname{Proj}_{C_{n+1}} x_{1}, \quad n \geq 0,
\end{array}\right.
$$

where $J_{s_{n}}=\left(I+s_{n} M\right)^{-1},\left\{s_{n}\right\}$ is a sequence in $(0,2 \beta)$, and $\left\{\alpha_{n}\right\}$ is a sequence in $(0,1)$. Assume that the following restrictions are satisfied:

(a) $0<a \leq s_{n} \leq b<2 \beta$;

(b) $0 \leq \alpha_{n} \leq c<1$,

where $a, b$, and c are real constants. Then the sequence $\left\{x_{n}\right\}$ converges strongly to $\operatorname{Proj}_{\mathcal{F}} x_{1}$.

Let $f: H \rightarrow(-\infty,+\infty]$ be a proper convex lower semicontinuous function. Then the subdifferential $\partial f$ of $f$ is defined as follows:

$$
\partial f(x)=\{y \in H: f(z) \geq f(x)+\langle z-x, y\rangle, z \in H\}, \quad \forall x \in H .
$$

From Rockafellar [34], we know that $\partial f$ is maximal monotone. It is not hard to verify that $0 \in \partial f(x)$ if and only if $f(x)=\min _{y \in H} f(y)$. 
Let $I_{C}$ be the indicator function of $C$, i.e.,

$$
I_{C}(x)= \begin{cases}0, & x \in C, \\ +\infty, & x \notin C .\end{cases}
$$

Since $I_{C}$ is a proper lower semicontinuous convex function on $H$, we see that the subdifferential $\partial I_{C}$ of $I_{C}$ is a maximal monotone operator. It is clear that $J_{s} x=P_{C} x, \forall x \in H$. Notice that $\left(B+\partial I_{C}\right)^{-1}(0)=\mathrm{VI}(C, B)$. Indeed,

$$
\begin{aligned}
x \in & \left(B+\partial I_{C}\right)^{-1}(0) \quad \Longleftrightarrow \quad 0 \in B x+\partial I_{C} x \\
& \Longleftrightarrow \quad-B x \in \partial I_{C} x \\
& \Longleftrightarrow \quad\langle B x, y-x\rangle \geq 0 \\
& \Longleftrightarrow \quad x \in \operatorname{VI}(C, B) .
\end{aligned}
$$

In the light of the above, the following is not hard to derive from Corollary 2.4.

Corollary 2.5 Let $C$ be a nonempty, closed, and convex subset of $H$. Let $S: C \rightarrow C$ be a nonexpansive mapping with a nonempty fixed point set and $B: C \rightarrow H$ be a $\beta$-inversestrongly monotone mapping. Assume that $\mathcal{F}:=F(S) \cap \mathrm{VI}(C, B)$ is not empty. Let $\left\{x_{n}\right\}$ be a sequence generated by the following iterative process:

$$
\left\{\begin{array}{l}
x_{1} \in C, \\
C_{1}=C, \\
y_{n}=\alpha_{n} x_{n}+\left(1-\alpha_{n}\right) S P_{C}\left(x_{n}-s_{n} B x_{n}\right), \\
C_{n+1}=\left\{v \in C_{n}:\left\|y_{n}-v\right\| \leq\left\|x_{n}-v\right\|\right\}, \\
x_{n+1}=\operatorname{Proj}_{C_{n+1}} x_{1}, \quad n \geq 0,
\end{array}\right.
$$

where $\left\{s_{n}\right\}$ is a sequence in $(0,2 \beta)$, and $\left\{\alpha_{n}\right\}$ is a sequence in $(0,1)$. Assume that the following restrictions are satisfied:

(a) $0<a \leq s_{n} \leq b<2 \beta$;

(b) $0 \leq \alpha_{n} \leq c<1$,

where $a, b$, and c are real constants. Then the sequence $\left\{x_{n}\right\}$ converges strongly to $\operatorname{Proj}_{\mathcal{F}} x_{1}$.

\section{Applications}

First, we consider the problem of finding a minimizer of a proper convex lower semicontinuous function.

Theorem 3.1 Let $f: H \rightarrow(-\infty,+\infty]$ be a proper convex lower semicontinuous function such that $(\partial f)^{-1}(0)$ is not empty. Let $\left\{x_{n}\right\}$ be a sequence generated by the following iterative 
process:

$$
\left\{\begin{array}{l}
x_{1} \in H, \\
C_{1}=H, \\
y_{n}=\arg \min _{s \in H}\left\{f(z)+\frac{\left\|z-x_{n}\right\|^{2}}{2 s_{n}}\right\}, \\
C_{n+1}=\left\{v \in C_{n}:\left\|y_{n}-v\right\| \leq\left\|x_{n}-v\right\|\right\}, \\
x_{n+1}=\operatorname{Proj}_{C_{n+1}} x_{1}, \quad n \geq 0,
\end{array}\right.
$$

where $\left\{s_{n}\right\}$ is a positive sequence such that $0<a \leq s_{n}$, where a is a real constant. Then the sequence $\left\{x_{n}\right\}$ converges strongly to $\operatorname{Proj}_{(\partial f)^{-1}(0)} x_{1}$.

Proof Putting $A=B=0, S=I$, and $\alpha_{n} \equiv 0$, we can immediately draw the desired conclusion from Theorem 2.1 .

Second, we consider the problem of approximating a common fixed point of a pair of nonexpansive mappings.

Theorem 3.2 Let $C$ be a nonempty, closed, and convex subset of $H$. Let $S: C \rightarrow C$ and $T: C \rightarrow C$ be a pair of nonexpansive mappings with a nonempty common fixed point set. Let $\left\{x_{n}\right\}$ be a sequence generated by the following iterative process:

$$
\left\{\begin{array}{l}
x_{1} \in C, \\
C_{1}=C, \\
z_{n}=\left(1-s_{n}\right) x_{n}+s_{n} T x_{n}, \\
y_{n}=\alpha_{n} x_{n}+\left(1-\alpha_{n}\right) S z_{n}, \\
C_{n+1}=\left\{v \in C_{n}:\left\|y_{n}-v\right\| \leq\left\|x_{n}-v\right\|\right\}, \\
x_{n+1}=\operatorname{Proj}_{C_{n+1}} x_{1}, \quad n \geq 0,
\end{array}\right.
$$

where $\left\{s_{n}\right\}$, and $\left\{\alpha_{n}\right\}$ are sequences in $(0,1)$. Assume that the following restrictions are satisfied:

(a) $0<a \leq s_{n} \leq b<1$;

(b) $0 \leq \alpha_{n} \leq c<1$,

where $a, b$, and $c$ are real constants. Then the sequence $\left\{x_{n}\right\}$ converges strongly to $\operatorname{Proj}_{F(S) \cap F(T)} x_{1}$.

Proof Putting $A=0, M=\partial I_{C}$, and $B=I-T$, we see that $B$ is $\frac{1}{2}$-inverse-strongly monotone. We also have $F(T)=\mathrm{VI}(C, B)$ and $P_{C}\left(x_{n}-s_{n} B x_{n}\right)=\left(1-s_{n}\right) x_{n}+s_{n} T x_{n}$. In view of (2.18), we can immediately obtain the desired result.

Let $F$ be a bifunction of $C \times C$ into $\mathbb{R}$, where $\mathbb{R}$ denotes the set of real numbers. Recall the following equilibrium problem in the terminology of Blum and Oettli [35] (see also Fan [36]):

Find $x \in C$ such that $F(x, y) \geq 0, \quad \forall y \in C$. 
To study the equilibrium problem (3.1), we may assume that $F$ satisfies the following conditions:

(A1) $F(x, x)=0$ for all $x \in C$;

(A2) $F$ is monotone, i.e., $F(x, y)+F(y, x) \leq 0$ for all $x, y \in C$;

(A3) for each $x, y, z \in C$,

$$
\limsup _{t \downarrow 0} F(t z+(1-t) x, y) \leq F(x, y)
$$

(A4) for each $x \in C, y \mapsto F(x, y)$ is convex and lower semi-continuous.

Putting $F(x, y)=\langle A x, y-x\rangle$ for every $x, y \in C$, we see that the equilibrium problem (3.3) is reduced to the variational inequality (1.1).

The following lemma can be found in [35] and [37].

Lemma 3.3 Let $C$ be a nonempty, closed, and convex subset of $H$ and $F: C \times C \rightarrow \mathbb{R}$ be a bifunction satisfying (A1)-(A4). Then, for any $s>0$ and $x \in H$, there exists $z \in C$ such that

$$
F(z, y)+\frac{1}{s}\langle y-z, z-x\rangle \geq 0, \quad \forall y \in C .
$$

Further, define

$$
T_{s} x=\left\{z \in C: F(z, y)+\frac{1}{s}\langle y-z, z-x\rangle \geq 0, \forall y \in C\right\}
$$

for all $s>0$ and $x \in H$. Then, the following hold:

(a) $T_{s}$ is single-valued;

(b) $T_{s}$ is firmly nonexpansive; that is,

$$
\left\|T_{s} x-T_{s} y\right\|^{2} \leq\left\langle T_{s} x-T_{s} y, x-y\right\rangle, \quad \forall x, y \in H ;
$$

(c) $F\left(T_{s}\right)=E P(F)$;

(d) $E P(F)$ is closed and convex.

Lemma 3.4 [30] Let $C$ be a nonempty, closed, and convex subset of $H, F$ be a bifunction from $C \times C$ to $\mathbb{R}$ which satisfies (A1)-(A4), and $A_{F}$ be a multivalued mapping of $H$ into itself defined by

$$
A_{F} x= \begin{cases}\{z \in H: F(x, y) \geq\langle y-x, z\rangle, \forall y \in C\}, & x \in C, \\ \varnothing, & x \notin C .\end{cases}
$$

Then $A_{F}$ is a maximal monotone operator with the domain $D\left(A_{F}\right) \subset C, E P(F)=A_{F}^{-1}(0)$, where $F P(F)$ stands for the solution set of (3.1), and

$$
T_{s} x=\left(I+s A_{F}\right)^{-1} x, \quad \forall x \in H, r>0,
$$

where $T_{s}$ is defined as in (3.3).

Finally, we consider finding a solution of the equilibrium problem. 
Theorem 3.5 Let $C$ be a nonempty, closed, and convex subset of $H$. Let $F: C \times C \rightarrow \mathbb{R}$ be a bifunction satisfying (A1)-(A4) such that $E P(F) \neq \emptyset$. Let $\left\{x_{n}\right\}$ be a sequence generated by the following iterative process:

$$
\left\{\begin{array}{l}
x_{1} \in C, \\
C_{1}=C, \\
y_{n}=\left(I+s_{n} A_{F}\right)^{-1} x_{n}, \\
C_{n+1}=\left\{v \in C_{n}:\left\|y_{n}-v\right\| \leq\left\|x_{n}-v\right\|\right\}, \\
x_{n+1}=\operatorname{Proj}_{C_{n+1}} x_{1}, \quad n \geq 0,
\end{array}\right.
$$

where $A_{F}$ is defined as (3.3), and $\left\{s_{n}\right\}$ is a positive sequence such that $0<a \leq s_{n}<\infty$, where $a$ is a real constant Then the sequence $\left\{x_{n}\right\}$ converges strongly to $\operatorname{Proj}_{F P(F)} x_{1}$.

Proof Putting $A=B=0, S=I$ and $\alpha_{n} \equiv 0$, we immediately reach the desired conclusion from Lemma 3.4.

\section{Competing interests}

The authors declare that they have no competing interests.

\section{Authors' contributions}

Both authors contributed equally to this work. Both authors read and approved the final manuscript.

\section{Author details}

Department of Mathematics, Hangzhou Normal University, Hangzhou, 310036, China.

\section{Authors' information}

Author's information

\section{Acknowledgements}

The first author was supported by the National Natural Science Foundation of China $(11071169,11271105)$, the Natural Science Foundation of Zhejiang Province (Y6110287, Y12A010095).

\section{Received: 27 June 2012 Accepted: 6 September 2012 Published: 25 September 2012}

\section{References}

1. Browder, FE: Nonlinear operators and nonlinear equations of evolution in Banach spaces. Proc. Symp. Pure Math. 18, 78-81 (1976)

2. Takahshi, W, Toyoda, M: Weak convergence theorems for nonexpansive mappings and monotone mappings, J. Optim. Theory Appl. 118, 417-428 (2003)

3. Polyak, BT: Introduction to Optimization. Optimization Software, New York (1987)

4. Calamai, PH, Moré, JJ: Projected gradient methods for linearly constrained problems. Math. Program. 39, 93-116 (1987)

5. Zhang, M: Iterative algorithms for common elements in fixed point sets and zero point sets with applications. Fixed Point Theory Appl. 2012, 21 (2012)

6. Byrne, $C:$ A unified treatment of some iterative algorithms in signal processing and image reconstruction. Inverse Probl. 20, 103-120 (2008)

7. Censor, Y, Elfving, T, Kopf, N, Bortfeld, T: The multiple-sets split feasibility problem and its applications for inverse problems. Inverse Probl. 21, 2071-2084 (2005)

8. Censor, Y, Bortfeld, T, Martin, B, Trofimov, A: A unified approach for inversion problems in intensity-modulated radiation therapy. Phys. Med. Biol. 51, 2353-2365 (2006)

9. Lopez, G, Martin, V, Xu, HK: Perturbation techniques for nonexpansive mappings with applications. Nonlinear Anal. $10,2369-2383(2009)$

10. Korpelevich, GM: An extragradient method for finding saddle points and for other problems. Ekonom. i Mat. Metody $12,747-756(1976)$

11. Qin, X, Cho, SY, Kang, SM: An extragradient-type method for generalized equilibrium problems involving strictly pseudocontractive mappings. J. Glob. Optim. 49, 679-693 (2011)

12. Anh, PN, Kim, JK, Muu, LD: An extragradient algorithm for solving bilevel pseudomonotone variational inequalities. J. Glob. Optim. 52, 627-639 (2012)

13. Nadezhkina, N, Takahashi, W: Weak convergence theorem by an extragradient method for nonexpansive mappings and monotone mappings. J. Optim. Theory Appl. 128, 191-201 (2006) 
14. Cho, SY, Kang, SM: Approximation of fixed points of pseudocontraction semigroups based on a viscosity iterative process. Appl. Math. Lett. 24, 224-228 (2011)

15. Cho, SY, Kang, SM: Zero point theorems of $m$-accretive operators in a Banach space. Fixed Point Theory 13, 49-58 (2012)

16. Kim, JK, Cho, SY, Qin, X: Hybrid projection algorithms for generalized equilibrium problems and strictly pseudocontractive mappings. J. Inequal. Appl. 2010, Article ID 312602 (2010)

17. Kang, SM, Cho, SY, Liu, Z: Convergence of iterative sequences for generalized equilibrium problems involving inverse-strongly monotone mappings. J. Inequal. Appl. 2010, 827082 (2010)

18. Ye, J, Huang, J: Strong convergence theorems for fixed point problems and generalized equilibrium problems of three relatively quasi-nonexpansive mappings in Banach spaces. J. Math. Comput. Sci. 1, 1-18 (2011)

19. Qin, X, Cho, YJ, Kang, SM: Convergence theorems of common elements for equilibrium problems and fixed point problems in Banach spaces. J. Comput. Appl. Math. 225, 20-30 (2009)

20. Qin, X, Cho, SY, Kang, SM: Strong convergence of shrinking projection methods for quasi- $\boldsymbol{\phi}$-nonexpansive mappings and equilibrium problems. J. Comput. Appl. Math. 234, 750-760 (2010)

21. Husain, S, Gupta, S: A resolvent operator technique for solving generalized system of nonlinear relaxed cocoercive mixed variational inequalities. Adv. Fixed Point Theory 2, 18-28 (2012)

22. Qin, X, Cho, SY, Kang, SM: On hybrid projection methods for asymptotically quasi- $\boldsymbol{\phi}$-nonexpansive mappings. Appl. Math. Comput. 215, 3874-3883 (2010)

23. Kim, JK: Strong convergence theorems by hybrid projection methods for equilibrium problems and fixed point problems of the asymptotically quasi- $\phi$-nonexpansive mappings. Fixed Point Theory Appl. 2011, 10 (2011)

24. Kim, JK, Cho, SY, Qin, X: Some results on generalized equilibrium problems involving strictly pseudocontractive mappings. Acta Math. Sci. 31, 2041-2057 (2011)

25. Chang, SS, Lee, HWJ, Chan, CK: A new method for solving equilibrium problem fixed point problem and variational inequality problem with application to optimization. Nonlinear Anal. 70, 3307-3319 (2009)

26. Qin, X, Kang, Jl, Cho, YJ: On quasi-variational inclusions and asymptotically strict pseudo-contractions. J. Nonlinear Convex Anal. 11, 441-453 (2010)

27. Tada, A, Takahashi, W: Weak and strong convergence theorems for a nonexpansive mappings and an equilibrium problem. J. Optim. Theory Appl. 133, 359-370 (2007)

28. Cho, SY, Kang, SM: Approximation of common solutions of variational inequalities via strict pseudocontractions. Acta Math. Sci. 32, 1607-1618 (2012)

29. Cho, SY, Qin, X, Kang, SM: Hybrid projection algorithms for treating common fixed points of a family of demicontinuous pseudocontractions. Appl. Math. Lett. 25, 854-857 (2012)

30. Takahashi, S, Takahashi, W, Toyoda, M: Strong convergence theorems for maximal monotone operators with nonlinear mappings in Hilbert spaces. J. Optim. Theory Appl. 147, 27-41 (2010)

31. Lv, S: Generalized systems of variational inclusions involving $(A, \eta)$-monotone mappings. Adv. Fixed Point Theory 1 1-14 (2011)

32. Kamimura, S, Takahashi, W: Weak and strong convergence of solutions to accretive operator inclusions and applications. Set-Valued Anal. 8, 361-374 (2000)

33. Rockafellar, RT: Characterization of the subdifferentials of convex functions. Pac. J. Math. 17, 497-510 (1966)

34. Rockafellar, RT: On the maximality of sums of nonlinear monotone operators. Trans. Am. Math. Soc. 149, 75-88 (1970)

35. Blum, E, Oettli, W: From optimization and variational inequalities to equilibrium problems. Math. Stud. 63, 123-145 (1994)

36. Fan, K: A minimax inequality and applications. In Shisha, O (ed.) Inequality, vol. III, pp. 103-113. Academic Press, New York (1972)

37. Combettes, PL, Hirstoaga, SA: Equilibrium programming in Hilbert spaces. J. Nonlinear Convex Anal. 6, 117-136 (2005)

doi:10.1186/1687-1812-2012-162

Cite this article as: Gu and Lu: Projection methods of iterative solutions in Hilbert spaces. Fixed Point Theory and Applications 2012 2012:162.

\section{Submit your manuscript to a SpringerOpen ${ }^{0}$ journal and benefit from:}

- Convenient online submission

- Rigorous peer review

- Immediate publication on acceptance

Open access: articles freely available online

- High visibility within the field

- Retaining the copyright to your article

Submit your next manuscript at $>$ springeropen.com 